\title{
Evaluation of the Relationship Between Metabolic Syndrome, Visceral Adiposity Index and Lipid Accumulation Product in Patients with Obesity
}

\author{
(D) Feray Akbaş, (1) Hanife Usta Atmaca, (1) Şerife Değirmencioğlu \\ University of Health Sciences Turkey, İstanbul Training and Research Hospital, Clinic of Internal Medicine, İstanbul, Turkey
}

Cite this article as: Akbaş F, Usta Atmaca H, Değirmencioğlu Ş. Evaluation of the Relationship Between Metabolic Syndrome, Visceral Adiposity Index and Lipid Accumulation Product in Patients with Obesity. J Acad Res Med 2021;11(1):56-61

\begin{abstract}
Objective: Visceral adiposity index (VAI) and lipid accumulation product index (LAPI) are the new methods to determine the visceral adiposity and to predict the cardiometabolic risks in patients with. In this study, it was aimed to determine whether VAI or LAPI could be a predictor for metabolic syndrome (MS) in obesity, and to evaluate their relationship with other biochemical and anthropometric parameters.

Methods: All patients who were admitted to the obesity outpatient clinic for the first time in January-February 2020 were included in the study. Age, gender, height, weight, body mass index, waist circumference (WC), hip circumference, waist/hip (W/H) ratio, biochemical parameters, and degree of hepatosteatosis were recorded. The presence of MS was determined according to the National Cholesterol Education Program Adult Treatment Panel-III criteria. VAI and LAPI were calculated according to fixed formulations. Results were evaluated by SPSS

Results: A total of 49 subjects, ( 48 females), with obesity were included in the study. Thirty-two patients (65.3\%) had MS. In the MS (+) group, fasting blood glucose (FBG), insulin resistance (HOMA-IR) and triglyceride (TG) levels, VAI, LAPI, diabetes mellitus and hypertension ratios were higher than the group with MS (-). A positive correlation was observed between VAI and LAPI. There was a positive correlation between the VAI and the TG value, and a negative correlation between the VAl and high density lipoprotein value. A positive correlation was observed between LBU and TG, FBG, HOMA-IR, WC, W/H ratios.

Conclusion: It is important to determine the comorbidities in obesity on a timely manner and to make the necessary interventions. With a simple formulation, VAl and LAPI can predict important health risks accompanying obesity.
\end{abstract}

Keywords: Obesity, metabolic syndrome, visceral adiposity index, lipid accumulation product index

\section{INTRODUCTION}

Obesity prevalence is increasing day-by-day in our country. It is a serious cause of morbidity and mortality, and puts a heavy burden on the health system. Therefore, it is vital to reveal the effects of obesity at an early stage and to take necessary precautions against the pathologies accompanying the obesity, as well as the treatment of it $(1,2)$.
Perhaps the most important parameter to be evaluated in obesity is the visceral adiposity. Visceral adipose tissue has been shown to cause cardio-metabolic pathologies, and the visceral adiposity index (VAI) is valuable in determining the risk for these diseases. VAl can now be measured using methods such as bioelectrical impedance analysis, dual energy X-ray absorptiometry, computed tomography, and magnetic resonance. However, since these

ORCID IDs of the authors: F.A. 0000-0001-5091-9160; H.U.A. 0000-0002-6591-4810; Ş.D. 0000-0002-3002-9133. 
methods are not practical, they bring costs and some of them are not available in every hospital/obesity center, new methods are needed to determine visceral adiposity (1-3).

VAI and lipid deposition product index (LAPI) are also new methods used in this subject. Both are essentially mathematical models calculated by anthropometric data, and are used to show visceral adiposity, adipose dysfunction, insulin resistance (HOMAIR), metabolic dysfunction, and cardio metabolic risk. Thus, with a simple formulation, they can predict the significant accompanying health risks and help take early action $(4,5)$.

In this study, it was aimed to evaluate the relationship between VAI and LAP in patients with and without metabolic syndrome (MS) in obesity, and to determine whether they could be a predictor of MS, as well as to evaluate their relationship with other biochemical parameters, anthropometric measurements, and hepatosteatosis.

\section{METHODS}

All patients who were admitted to the obesity outpatient clinic for the first time in January-February 2020 were included in the study. Age, gender, height, weight, body mass index (BMI), waist circumference $(\mathrm{WC})$, hip circumference $(\mathrm{HC})$, waist/hip ratio (WHR), biochemical parameters [fasting blood glucose (FBG), triglyceride $(T G)$, high density lipoprotein (HDL), HOMA-IR], degree of hepatosteatosis (detected by abdominal ultrasonography), blood pressure arterial (TA) value, presence of diabetes mellitus (DM) and hypertension (HT) were recorded. Presence of MS was determined according to National Cholesterol Education Program Adult Treatment Panel-III (NCEP-ATP-III) criteria. VAl and LAPI were calculated according to the fixed formulations (Table 1, 2). The results were analyzed on SPSS.

The study was conducted in accordance with the 1964 Helsinki Declaration. Ethics committee approval was obtained from the University of Health Sciences Turkey, İstanbul Training and Research Hospital Ethics Committee (approval number: 2254, tarih: 27.04.2020) and informed consent was obtained from the patients.

Table 1. VAI Formulation for male and female patients

- Male VAI : $\left[\frac{W C(\mathrm{~cm})}{\left\{39.68+\left(1.88 \times \mathrm{BMI}\left(\frac{\mathrm{gg}}{\mathrm{m}}\right)\right)\right\}}\right] \times\left[\frac{\mathrm{TG}(\mathrm{mmol} / \mathrm{l})}{1.03}\right] \times\left[\frac{1.31}{\mathrm{HDL}(\mathrm{mmol} / \mathrm{l})}\right]$
- Female VAI : $\left[\frac{W C(\mathrm{~cm})}{\left\{36.58+\left(1.89 \times \mathrm{BMI}\left(\frac{\mathrm{kg}}{\mathrm{m}}\right)\right)\right\}}\right] \times\left[\frac{\mathrm{TG}(\mathrm{mmol} / \mathrm{l})}{0.81}\right] \times\left[\frac{1.52}{\mathrm{HDL}(\mathrm{mmol} / \mathrm{l})}\right]$

VAI: Visceral adiposity index, WC: waist circumference, BMI: body mass index, TG: triglyceride, HDL: high density lipoprotein

\section{Table 2. LAPI Formulation for male and female patients}

Male LAPI $=[$ waist $(\mathrm{cm})-65] \times$ TG concentration $(\mathrm{mmol} / \mathrm{L})$ Female LAPI $=[$ waist $(\mathrm{cm})-58] \times \mathrm{TG}$ concentration $(\mathrm{mmol} / \mathrm{L})$ LAP: lipid accumulation product index, TG: triglyceride

\section{Statistical Analysis}

In the descriptive statistics of the data; mean, standard deviation, median lowest, highest, frequency and ratio values were used. The distribution of variables was measured with the KolmogorovSimonov test. Mann-Whitney $U$ test and Independent Sample test were used in the analysis of quantitative independent data. Chi-square test was used in the analysis of categorical data, and Fisher's exact test was used when chi-square test conditions were not met. SPSS 26.0 program was used in the analysis.

\section{RESULTS}

A total of 49 people, 48 females and 1 male, with obesity were included in the study. Thirty-two patients (65.3\%) had MS. The mean and median values of the data for the parameters are shown on Table 3.

Age, gender distribution, height, weight, WC, HC, WHR, BMI values of the patients with and without MS did not show a significant difference $(p>0.05)$. In the group with MS $(+), F B G$, HOMA-IR and TG levels, VAI, LAPI, DM and HT ratios were significantly higher $(p<0.05)$ than the group with MS $(-)$. HDL values and hepatosteatosis degrees of the patients in the group with and without MS did not show a significant difference $(p>0.05)$ (Table 4, Figure 1).

Significant positive correlation $(p<0.05)$ was observed between the visceral adipocyte index and lipid deposition product. There was a significant positive correlation $(p<0.05)$ between visceral adipocyte index and TG value, and a significant negative correlation $(p<0.05)$ between visceral adipocyte index HDL value. There was no significant correlation $(p>0.05)$ between VAl and age, FBG, HOMA-IR, BMI, WC, HC, WHR (Table 5).

A significant positive correlation $(p<0.05)$ was observed between lipid deposition product and TG, FBG, HOMA-IR, WC, WHR values. There was no significant correlation $(p<0.05)$ with age, $\mathrm{HDL}, \mathrm{BMI}$, and $\mathrm{HC}$ (Table 5).

The age, gender distribution, height and weight values of the patients in the group with hepatosteatosis grade (0-1) and grade (2-3) did not differ significantly $(p>0.05)$. The BMl of the patients in the group with hepatosteatosis grade (2-3) was significantly higher $(p<0.05)$ than the patients in the hepatosteatosis grade $(0-1)$ group. WC, HC, WHR, FBG, HOMA-IR, TG, HDL, VAl, LAPI values, $D M, H T$, MS ratios values did not differ significantly $(p>0.05)$ in the group with hepatosteatosis grade (0-1) and grade (2-3) (Table 6).

\section{DISCUSSION}

Obesity is the abnormal accumulation of fat in the body that poses a health risk (6). Most of the adipose tissue consists of white adipocytes, although there are also beige/brown adipocytes in humans. The white adipose tissue responsible for energy storage is mainly located under the skin. However, when visceral steatosis causes ectopic steatosis in the liver, heart and muscles, it causes low-level chronic inflammation, HOMA-IR, and consequently metabolic complications, in addition to cardiovascular diseases $(7,8)$. 
Table 3. General data of the parameters investigated

\begin{tabular}{|c|c|c|c|c|}
\hline & & Min-Max & Median & $\begin{array}{l}\text { Mean } \pm \text { SD/ } \\
(n, \%)\end{array}$ \\
\hline Age & & $20.0-64.0$ & 51.0 & $49.1 \pm 10.8$ \\
\hline & Female & - & - & 48 (98.0\%) \\
\hline Sertal & Male & - & - & $1(2.0 \%)$ \\
\hline Height & & $117.0-177.0$ & 160.0 & $160.0 \pm 8.9$ \\
\hline Weight & & $67.0-134.0$ & 97.0 & $99.6 \pm 18.3$ \\
\hline Body mass index & & $28.8-53.3$ & 39.1 & $38.7 \pm 6.4$ \\
\hline Waist circumferer & & $90.0-132.0$ & 113.0 & $113.0 \pm 9.5$ \\
\hline Hip circumferenc & & $106.0-167.0$ & 130.0 & $130.1 \pm 12.2$ \\
\hline Waist/hip ratio & & $0.7-1.0$ & 0.9 & $0.9 \pm 0.1$ \\
\hline Fasting blood glu & cose & $79.0-187.0$ & 99.0 & $105.0 \pm 21.5$ \\
\hline HOMA-IR & & $0.1-7.6$ & 2.5 & $2.6 \pm 1.5$ \\
\hline Visceral adipocyt & e index & $1.7-19.0$ & 5.3 & $6.0 \pm 3.2$ \\
\hline $\begin{array}{l}\text { Lipid accumulatic } \\
\text { product }\end{array}$ & & 1792.0-18148 & 8250.0 & $8382.6 \pm 3563.4$ \\
\hline Triglyceride & & $56.0-349.0$ & 150.0 & $152.0 \pm 59.5$ \\
\hline $\mathrm{HDL}$ & & $38.0-102.0$ & 50.0 & $53.0 \pm 12.2$ \\
\hline Diahetec & $(-)$ & - & - & 38 (77.6\%) \\
\hline Dianetes & $(+)$ & - & - & $11(22.4 \%)$ \\
\hline IIT & $(-)$ & - & - & 39 (79.6\%) \\
\hline 111 & $(+)$ & - & - & $10(20.4 \%)$ \\
\hline Henatectortacic & $0-1$ & - & - & 17 (34.7\%) \\
\hline Hepatosteatosis & $2-3$ & - & - & 32 (65.3\%) \\
\hline & 0 & - & - & $4(8.2 \%)$ \\
\hline Hepatosteatosis & 1 & - & - & $13(26.5 \%)$ \\
\hline grade & 2 & - & - & $28(57.1 \%)$ \\
\hline & 3 & - & - & 4 (8.2\%) \\
\hline Metabolic & $(-)$ & - & - & 17 (34.7\%) \\
\hline syndrome & $(+)$ & - & - & 32 (65.3\%) \\
\hline
\end{tabular}

Min: minimum, Max: maximum, SD: standard deviation, HOMA-IR: insulin resistance, HDL: high density lipoprotein, HT: hypertension

MS is one of the diseases accompanying obesity. NCEP-ATP-III criteria are commonly used for identification purposes. Increase in WC, being diagnosed with TA or under HT treatment, high BG or being under DM treatment, high TG and low HDL are the diagnostic criteria. It is important to screen these criteria in individuals with obesity and to take the necessary precautions in the presence of MS in order to prevent obesity-related morbidity and mortality $(8,9)$. In our study, MS is present in two-thirds of the patients, and FBG, HOMA-IR, TG level, VAl and LAPI were found to be high in this group.

VAI and LAPI are also new methods that have been used to determine visceral adiposity. It is a formulation that uses simple anthropometric measurements such as WC and BMI and biochemical parameters such as TG and HDL. Fixed values vary for men and women (5).
VAI was positively correlated with peripheral glucose use in euglycemic and hyperinsulinemic clamp studies. Many studies have been published showing that it is associated with type $2 \mathrm{DM}$, MS, cardiovascular diseases and polycystic ovary syndrome (10). In our study, in the group with MS, VAl was found to be higher than the group without MS and correlated with atherogenic dyslipidemia profile. However, no relationship was found between HOMA-IR and BMI. It has led to the thought that VAl has a stronger relationship with the diagnostic combination of the parameters that constitute the MS, rather than a single effect. As a matter of fact, different studies have shown the relationship between VAI and MS in support of this idea $(11,12)$.

The LAPI is based on a formulation using WC and TG level. It was found to be more effective than $\mathrm{BMI}$ and WC in reflecting HOMAIR and predicting cardiovascular disease risk $(4,13)$. It is associated with glucose/insulin homeostasis and dietary pattern as well as anthropometric data and is an inexpensive alternative to indirect visceral adiposity measurement method (14). In the study conducted by Chiang and Koo (15), LAPI was seen to predict MS. Similarly, in our study, LAPI was found to be high in patients with MS.

VAl is usually high in hepatosteatosis, but there are studies showing that it is not directly related to steatosis and has poor diagnostic power in this regard. WC is seen as a stronger predictor for liver fattening $(16,17)$. Although the degree of hepatosteatosis was found to be associated with BMI in our study, the MS was not found to be associated with VAI or LAPI in parallel with these data. However, it is thought that VAI may be a marker for adipose tissue dysfunction, especially in the absence of MS (18).

\section{Study Limitations}

The limited number of patients and the fact that the same parameters were not examined in individuals without obesity are the limitations of this study.

\section{CONCLUSION}

In individuals with obesity, VAl and LAPI are associated with MS and the parameters that constitute MS. It can be calculated with a simple formulation and can be used as a practical tool in determining the level of inflammation, adipocyte dysfunction, and the metabolic and cardiovascular risks.

Ethics Committee Approval: The study was approved by the University of Health Sciences Turkey, İstanbul Training and Research Hospital, Clinic Research Ethics Committee (approval number: 2254, date: 27.04.2020).

Informed Consent: Informed consent was obtained from the patients.

Peer-review: Externally peer-reviewed.

Author Contributions: Surgical and Medical Practices - F.A.; Concept - F.A., H.U.A., Ş.D.; Design - F.A., H.U.A., Ş.D.; Data Collection and/or Processing - F.A., S..D.; Analysis and/or Interpretation - F.A., Ş.D.; Literature Search - F.A., H.U.A., S..D.; Writing Manuscript - F.A., H.U.A.

Conflict of Interest: The authors have no conflict of interest to declare.

Financial Disclosure: The authors declared that this study has received no financial support. 
Table 4. Parameters investigated according to the presence of metabolic syndrome

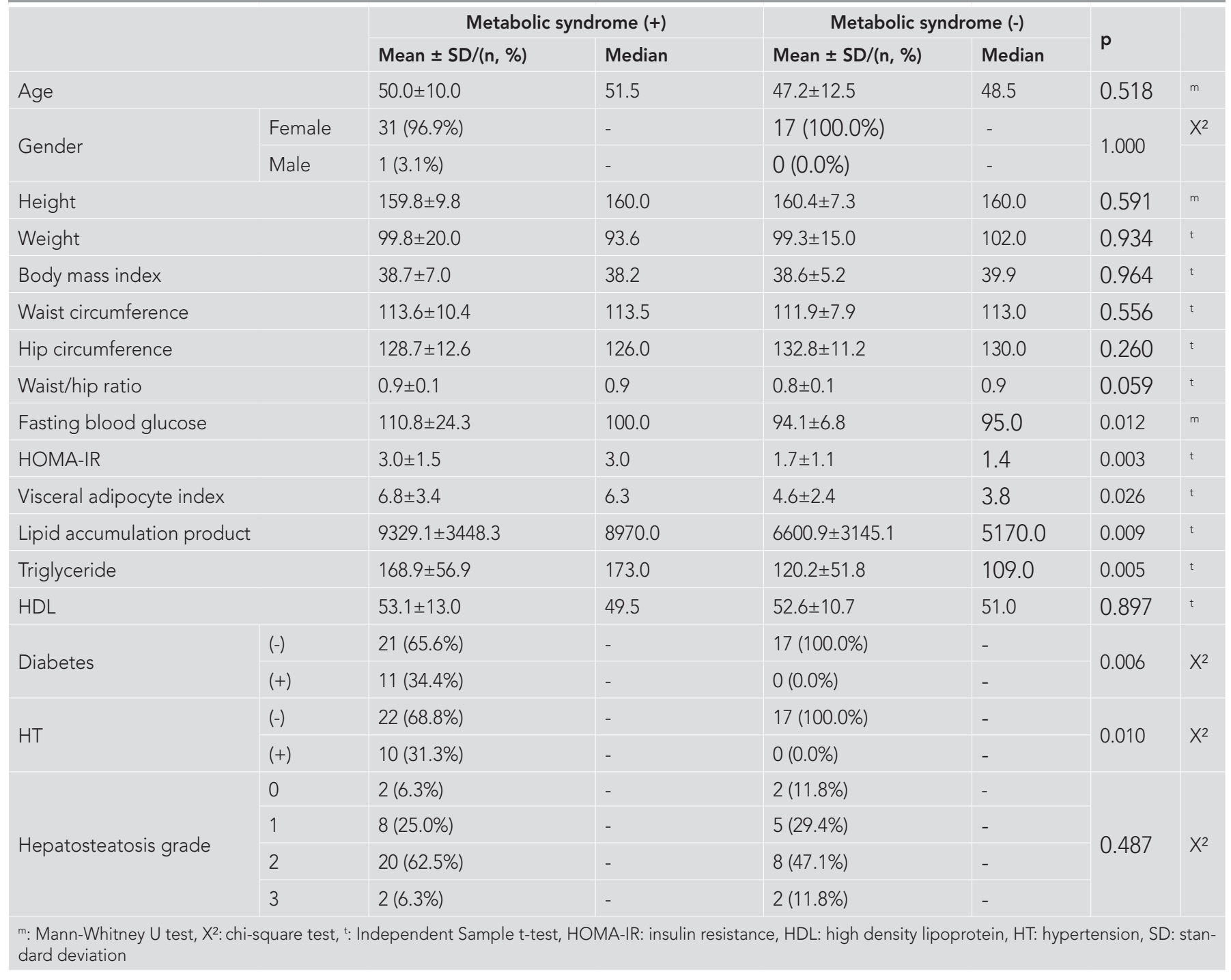
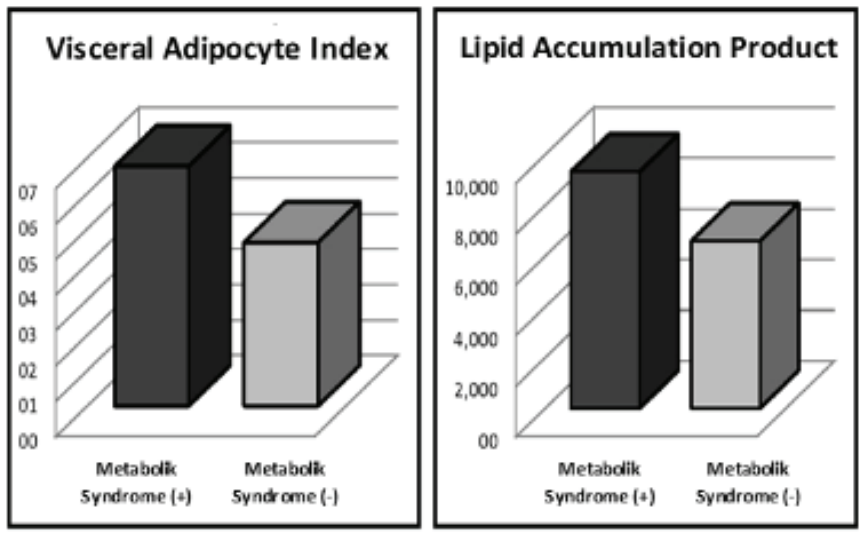

Figure 1. MS and VAI-LAPI box plot MS: metabolic syndrome, VAI: visceral adiposity index, LAPI: lipid accumulation product index
Table 5. VAI, LAP and research parameters

\begin{tabular}{|l|l|l|l|l|}
\hline & \multicolumn{3}{|l|}{$\begin{array}{l}\text { Visceral adipocyte } \\
\text { index }\end{array}$} & \multicolumn{2}{l}{$\begin{array}{l}\text { Lipid } \\
\text { accumulation } \\
\text { product }\end{array}$} \\
\hline & $\mathbf{r}$ & $\mathbf{p}$ & $\mathbf{r}$ & $\mathbf{p}$ \\
\hline $\begin{array}{l}\text { Lipid accumulation } \\
\text { product }\end{array}$ & 0.835 & 0.000 & - & - \\
\hline Age & 0.046 & 0.755 & 0.137 & 0.355 \\
\hline Triglyceride & 0.924 & 0.000 & 0.915 & 0.000 \\
\hline HDL & -0.603 & 0.000 & -0.222 & 0.125 \\
\hline Fasting blood sugar & 0.268 & 0.063 & 0.339 & 0.017 \\
\hline HOMA-IR & 0.182 & 0.211 & 0.290 & 0.044 \\
\hline Body mass index & -0.208 & 0.152 & 0.116 & 0.429 \\
\hline Waist circumference & -0.037 & 0.800 & 0.372 & 0.009 \\
\hline Hip circumference & -0.160 & 0.274 & 0.069 & 0.636 \\
\hline Waist/hip ratio & 0.227 & 0.117 & 0.389 & 0.006 \\
\hline $\begin{array}{l}\text { Spearman Correlation. } \\
\text { HDL: high density lipoprotein, }\end{array}$ & HOMA-IR: insulin resistance & \\
\hline
\end{tabular}


Table 6. Hepatosteatosis and research parameters

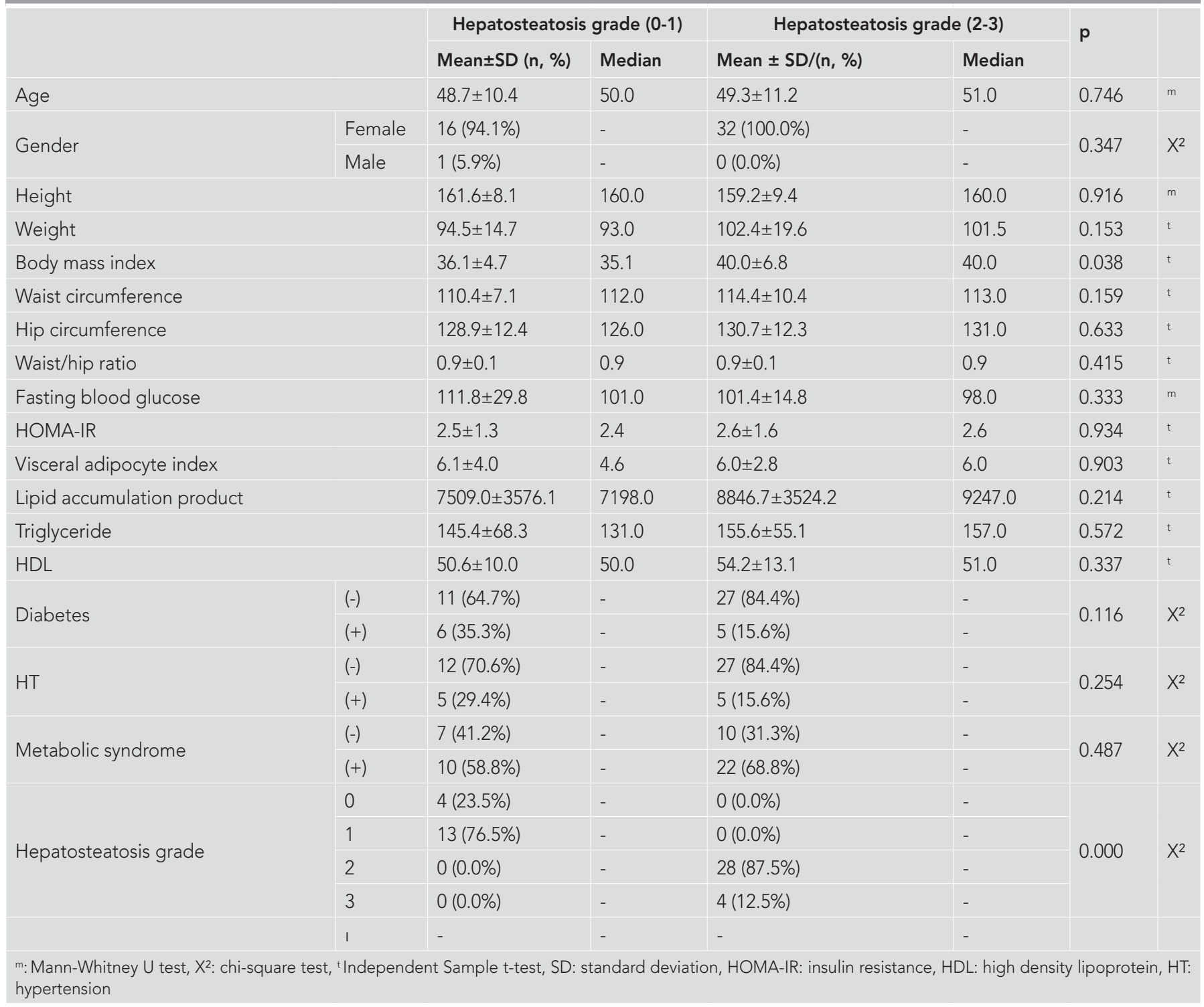

\section{REFERENCES}

1. Yumuk V, Tsigos C, Fried M, Schindler K, Busettov L, Micic D, et al. European guidelines for obesity management in adults Obes Facts 2015; 8: 402-24.

2. Frühbeck G, Busetto L, Dicker D, Yumuk V, Goossens GH, Hebebrand J, et al. Position statement on a diagnostic term with clinical and scientific implications. Obes Facts 2019; 12: 131-6.

3. Elffers TW, de Mutsert R, Lamb HJ, de Roos A, Willems van Dijk K, Rosendaal FR, et al. Body fat distribution, in particular visceral fat, is associated with cardiometabolic risk factors in obese women. PLoS One 2017; 12 :e0185403. doi: 10.1371/journal.pone.0185403.

4. Xia C, Li R, Zhang S, Gong L, Ren W, Wang Z, et al. Lipid accumulation product is a powerful index for recognizing insulin resistance in nondiabetic individuals. Eur J Clin Nutr 2012; 66: 1035-8.

5. Amato MC, Giordano C, Galia M, Criscimanna A, Vitabile S, Midiri M, et al. Visceral Adiposity Index: a reliable indicator of visceral fat function associated with cardiometabolic risk. Diabetes Care 2010; 33: 920-2.

6. WHO Health Topics: Obesity. Avaialable from: https://www.who.int/ topics/obesity/en/

7. Gaggini M, Saponaro C, Gastaldelli A. Not all fats are created equal: adipose vs. ectopic fat, implication in cardiometabolic diseases. Horm Mol Biol Clin Investig 2015; 22: 7-18.
8. TEMD Obezite, Lipid Metabolizmasi, Hipertansiyon Çalişma Grubu. Obezite Tanı ve Tedavi Kılavuzu. Ankara: Türkiye Endokrinoloji ve Metabolizma Derneği; 2019. Available from: https://temd.org.tr/admin/ uploads/tbl_kilavuz/20190506163904-2019tbl_kilavuz5ccdcb9e5d.pdf

9. Grundy SM, Cleeman JI, Daniels SR, Donato KA, Eckel RH, Franklin $\mathrm{BA}$, et al. Diagnosis and management of the metabolic syndrome: an American Heart Association/National heart, lung, and blood institute scientific statement. Circulation 2005; 112: 2735-52.

10. Hiya A, Kiran A, Anju J. Visceral adiposity index: Simple Tool for assessing cardiometabolic risk in women with polycystic ovary syndrome. Indian J Endocrinol Metab 2019; 23: 232-7.

11. Ray L, Ravichandran K, Nanda SK. Comparison of lipid accumulation product index with body mass index and waist circumference as a predictor of metabolic syndrome in Indian population. Metab Syndr Relat Disord 2018; 16: 240-5.

12. Pekgor S, Duran C, Berberoglu U, Eryilmaz MA. The Role of visceral adiposity index levels in predicting the presence of metabolic syndrome and Insulin resistance in overweight and obese patients. Metab Syndr Relat Disord 2019; 17: 296-302.

13. Hosseinpanah F, Barzin M, Erfani H, Serahati S, Tehrani FR, Azizi F. Lipid accumulation product and insulin resistance in Iranian PCOS prevalence study. Clin Endocrinol (Oxf) 2014; 81: 52-7. 
14. Mohsen M, Hong-kai G, Andre Pascal K. Lipid accumulation product and visceral adiposity index are associated with dietary patterns in adult Americans, Medicine (Baltimore) 2018; 97: e0322. doi: 10.1097/ MD.0000000000010322.

15. Chiang J, Koo M. Lipid accumulation product: a simple and accurate index for predicting metabolic syndrome in Taiwanese people aged 50 and over. BMC Cardiovasc Disord 2012; 12: 78.

16. Vassilatou E, Lafoyianni S, Vassiliadi DA, loannidis D, Paschou SA, Mizamtsidi $M$, et al. Visceral adiposity index for the diagnosis of nonalcoholic fatty liver disease in premenopausal women with and without polycystic ovary syndrome. Maturitas 2018; 116: 1-7.

17. Vongsuvanh R, George J, McLeod D, van der Poorten D. Visceral adiposity index is not a predictor of liver histology in patients with nonalcoholic fatty liver disease. J Hepatol 2012; 57: 392-8.

18. Amato MC, Giordano C. Visceral adiposity Index: an Indicator of adipose tissue dysfunction. Int J Endocrinol 2014:730827. Doi: 10.1155/2014/730827. 